\title{
Potency and acceptability of oral misoprostol compared with vaginal misoprostol prior to first trimester abortion
}

\author{
Varsha Kotwal \\ Correspondence: Dr Varsha Kotwal, Senior Consultant, Obstetrics and Gynecology, (Jammu \\ and Kashmir). Email - varshakotwal963@gmail.com
}

Distributed under Attribution-NonCommercial - Share Alike 4.0 International (CC BY-NC-SA 4.0)

\begin{abstract}
Objectives: Present study was done to assess the effectiveness and acceptability of oral misoprostol compared with vaginal misoprostol for cervical priming before termination of first trimester pregnancy. Methodology: One hundred twenty patients who are voluntarily opting for termination of pregnancy were randomly divided into oral misoprostol group and vaginal misoprostol group. The patients were given $400 \mu \mathrm{gm}$ of misoprostol either by oral route or by vaginal administration 4 hours before surgical termination of pregnancy. The data collection was done which was based on questionnaire system, vaginal bleeding and abdominal pain was noted. Results: There was no significant differences in oral and vaginal misoprostol as far as cervical dilatation is concerned $(5.63 \mathrm{~mm}$ versus $5.43 \mathrm{~mm})$. The women in vaginal group experienced more bleeding $42 \%$ versus $24 \%$ in oral group. A total of $89 \%$ patients in oral misoprostol group expressed their satisfaction whereas a total number of $75 \%$ patients in vaginal misoprostol group were satisfied. Conclusion: The effectiveness of oral misoprostol is similar to vaginal misoprostol for cervical ripening but women are more satisfied in oral misoprostol group than vaginal group.
\end{abstract}

Keywords: Oral misoprostol, first trimester, pregnancy termination, cervical ripening.

According to WHO, the definition of abortion is the termination of pregnancy before 20 weeks gestation or fetus less than $500 \mathrm{gms}$ of weight ${ }^{1}$. Vacuum aspiration is the method of choice for termination of first trimester pregnancy. Cervical injury during surgical termination can be reduced by making the cervix soft and easy to dilate with the help of priming agents like prostaglandin $\mathrm{E}_{1}$, analogue misoprostol. Recently, prostaglandin $\mathrm{E}_{1}$ analogue misoprostol has caught much attention as cervical priming agent. Misoprostol was originally marketed for prevention of peptic ulcers caused by Prostaglandin synthetase inhibitor (NSAIDS) but now it has a widespread role in obstetric practice specially as a cervical priming agent. Prostaglandins are used in medical termination of first trimester pregnancy also ${ }^{2}$. Prostaglandins are a group of modified long chain fatty acids. The main prostaglandins used clinically are three $\left(E_{1}, E_{2}\right.$ and $\left.F_{2} \alpha\right)$. Prostaglandin $E_{1}$ analogue misoprostol has been found much better alternative for cervical ripening. Surgical procedure to terminate pregnancy include dilation and curettage, vacuum aspiration which have complications like cervical rupture, perforation of uterus and even can cause injury to viscera ${ }^{3}$. Therefore, cervical priming with misoprostol becomes extremely

Received: $3^{\text {rd }}$ May 2019. Accepted: $18^{\text {th }}$ October 2019.

Kotwal V. Potency and acceptability of oral misoprostol compared with vaginal misoprostol prior to first trimester abortion. The New Indian Journal of OBGYN. 2020; 6(2): 79-82. 
important prior to termination of pregnancy.

Misoprostol tablets are available under the brand name

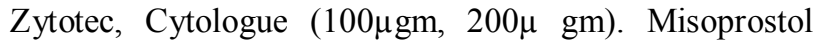
(prostaglandin $\mathrm{E}_{1}$ analogue) is administered vaginally as well as orally before surgical termination of first trimester abortion. Vaginal misoprostol is administered 4 hours prior to surgical termination of first trimester pregnancy in a dose of $400 \mu \mathrm{gm}$. The results are effective dilatation with very less side effects ${ }^{4}$. Misoprostol is an effective myometrial stimulant selectively binding to $\mathrm{EP}_{2}$ and $\mathrm{EP}_{3}$ prostanoid receptors thus making it very effective for cervical priming. It has been found that oral route of administration has been more acceptable among women ${ }^{5}$. Our study compares the effectiveness, acceptability and side effects of oral misoprostol and vaginal administration of misoprostol in cervical ripening before termination of
2- Pain which requires no analgesies

3- Pain which requires analgesies.

Vaginal bleeding was noted on a scale of $0-3$ :

0 - No bleeding

1- Minimal bleeding

2- Bleeding like menstrual flow

3- Heavy bleeding.

Termination of pregnancy was done using Karmans Cannula of $6-10 \mathrm{~mm}$ diameter. Cervical dilatation was measured using Hegars dilators starting from smaller dilators until a dilator entered the cervical os without resistance. The facts were entered in the statistical package for social sciences, arithmetic mean and standard deviation were calculated.

Results

In the present study, 120 women were randomized into first trimester pregnancy.

\section{Materials and methods}

This study was conducted in a Govt. hospital in Jammu and Kashmir. Case under study consisted of one hundred twenty patients who are voluntarily opting for termination of pregnancy by vacuum aspiration. All patients underwent a detailed physical and obstetrical examination. Complete haemogram including haemoglobin level, blood grouping and typing was done. Informed consent was taken from all the women willing to participate in this study. Gestational age was calculated from last menstrual
Table 1: Characteristics of patients undergoing cervical priming using oral and vaginal misoprostol

\begin{tabular}{llll}
\hline Characteristics & Oral $(\mathbf{N}=\mathbf{5 2})$ & Vaginal & $\mathbf{P}$ \\
\hline & & $\mathbf{( N = 6 8 )}$ & value \\
\cline { 2 - 4 } Age (years) & $26.76 \pm 6.37$ & $27.62 \pm 5.0$ & 0.322 \\
Parity & $2.59 \pm 1.30$ & $3.01 \pm 0.98$ & 0.078 \\
Gestational period (days) & $58.86 \pm 12.64$ & $59.96 \pm 7.18$ & 0.586 \\
BMI & $22.21 \pm 2.96$ & $22.34 \pm 3.30$ & 0.834 \\
\hline \multicolumn{2}{c}{ two groups of oral misoprostol $(\mathrm{n}=52)$ and } & vaginal
\end{tabular}

misoprostol $(n=70)$. Out of which 2 women from vaginal group were excluded because they had bleeding from administration of vaginal misoprostol. Demographic aspects of the two groups were almost similar (Table 1). period and in case the dates were not sure, ultrasonography was done to confirm the dates.

Table 2: Outcome in both the groups

Exclusion criteria: Women who Cervical dilatation have allergy to misoprostol, previous uterine surgery and patients having medical disorders.

Pregnant women were randomly divided into oral misoprostol group and vaginal misoprostol group. The patients were given $400 \mu \mathrm{gm}$ of misoprostol either by oral route or by vaginal administration 4 hours before surgical termination of pregnancy i.e by vacuum aspiration. The \begin{tabular}{lll} 
Oral $(\mathbf{N}=\mathbf{5 2})$ & Vaginal $(\mathbf{N}=\mathbf{6 8})$ & P value \\
\hline 46 & 50 & 0.055
\end{tabular} $5.63 \quad 5.43$ 0.748

\begin{tabular}{llll}
\hline Outcomes & Oral $(\mathbf{N}=\mathbf{5 2})$ & Vaginal $(\mathbf{N}=\mathbf{6 8})$ & P value \\
\hline Women acceptability (satisfied) & 46 & 50 & 0.055 \\
Cervical dilatation & 5.63 & 5.43 & 0.748 \\
\hline
\end{tabular}
The dilatation of cervix among two groups did not differ significantly (Table 2). There were no significant differences in oral and vaginal misoprostol as far as cervical dilatation is concerned $(5.63 \mathrm{~mm}$ versus $5.43 \mathrm{~mm})$. A total of $89 \%$ patients in oral misoprostol group expressed their satisfaction whereas a total number of $75 \%$ patients in vaginal misoprostol group were satisfied. data collection was done which was based on questionnaire system, vaginal bleeding and abdominal pain was noted.

Abdominal pain graded on 0-3 scale:

0 - No pain

1- Mild pain

Table 3: Side effects

\begin{tabular}{llll}
\hline Side effects & Oral $(\mathbf{N}=52)$ & Vaginal $(\mathbf{N}=\mathbf{6 8})$ & P value \\
\hline Vomiting & $5 \%$ & $2.5 \%$ & 0.574 \\
Abdominal pain & $5 \%$ & $16 \%$ & 0.922 \\
Preoperative vaginal bleeding & $24 \%$ & $42 \%$ & 0.55 \\
\hline
\end{tabular}

The women in vaginal group experienced more bleeding $42 \%$ versus $24 \%$ in oral group. Questionnaire responses 
showed that incidence of side effects like nausea, vomiting, diarrhea were not significantly different among the two groups. The number of patients having pain and fever were also almost similar in both the groups (Table 3). No major side effects such as excessive vaginal bleeding or uterine perforation were seen in both the groups. The duration of bleeding after termination of pregnancy was similar in both groups with median of 5 days in oral misoprostol group and 6 days in vaginal misoprostol group.

\section{Discussion}

Misoprostol is a stable and synthetic prostaglandin E1 analogue ${ }^{6}$ and is presently known for its highest consumption in obstetrics and gynaecology. The drug absorption rate varies depending on the method of administration and dose. Prostaglandins are extensively used for cervical ripening before vacuum aspiration for first trimester pregnancy. Studies have shown that misoprostol is far more effective than placebo ${ }^{7,8}$ and as effective as gameprostone and dinoprostone 9,10 in relation to basal cervical dilatation before termination of first trimester pregnancy.

Our study showed that a higher percentage of women in oral misoprostol group showed satisfaction as compared to vaginal misoprostol group. The study also suggests that oral administration of misoprostol is an effective alternate measure to vaginal administration. The percentage of side effects was also same in both the groups. Sublingual route has also been evaluated as an alternative to vaginal and oral misoprostol. Studies ${ }^{11}$ have shown the pharmacokinetics of different routes of administration in Asian women. Women given sublingual misoprostol showed peak serum levels as compared to women of vaginal and oral route. Similar results have also been evaluated ${ }^{12}$ in which peak serum levels were achieved more in sublingual group as compared to oral group. So, sublingual administration becomes an extra choice in women who wish to avoid vaginal administration. As far as side effects are concerned, they are more in sublingual groups as compared to vaginal group ${ }^{13}$. Present study showed that oral misoprostol achieves similar cervical dilatation when compared with vaginal misoprostol. The side effects in both the groups are almost similar which is comparable with other studies ${ }^{14}$.

\section{Conclusion}

This study suggests that the effectiveness of oral misoprostol is similar to vaginal misoprostol for preinduction cervical ripening but since women are more satisfied in oral misoprostol group than vaginal group. It reflects that oral misoprostol becomes an alternative for vaginal administration.

\section{Conflict of interest: None. Disclaimer: Nil.}

\section{References}

1. Cunningham FG, Leveno KJ, Bloom SL, Hauth JC, Rouse DJ, Spong CY. Williams obstetrics 24 ed. NewYork: Mc Graw-Hill; 2015.p.316-17.

2. Meckstroth KR, Darney PD. Prostaglandins for first trimester termination. Best Pract Res Clin obstet Gynaecol. 2003; 17(5):745-63.

3. Muffley PE, Stitely ML, Gherman RB. Early intrauterine pregnancy failure: a randomized trial of medical versus surgical treatment. Am J Obstet Gynecol. 2002; 187(2): 321-6

4. Singh K, Fong YF, Prasad RNV. A comparative study using two dose regimens $(200 \mu \mathrm{g}$ or $400 \mu \mathrm{g})$ of vaginal misoprostol for pre-operative cervical dilatation in first trimester nulliparae. Br. J. Obstet. Gynaecol. 1998; 105(4): 413-7.

5. Ho PC, Ngai SW, Liu KL, Wong GCY, Lee SWH. Vaginal misoprostol compared with oral misoprostol in termination of second trimester pregnancy. Obstet. Gynaecol. 1997; 90(5): 735-8.

6. Silverstein FE. Improving the gastrointestinal safety of NSAIDS: the development of misoprostol from hypothesis to clinical practice. Dig Dis Sci. 1998; 43(3): 447-58.

7. Singh K, Fong YF, Prasad RNV, Dong F. Vaginal misoprostol for preabortion cervical priming is there an optimal evaluation time in interval? BJOG. 1999; 106: 266-9.

8. Ngai SW, Tang OS, Lao T. Oral misoprostol versus placebo for cervical dilatation before vacuum aspiration in first trimester pregnancy. Hum Reprod. 1995; 10: 1220-22.

9. Schaub B, Fuhrer P, Sainte-Rose D. Randomized study of sulprostone versus misoprostol in the cervical preparation before elective abortion in nulliparous women. J Gynecol Obstet Biol Reprod (Paris). 1995; 24: 505-8. 
The New Indian Journal of OBGYN. 2020 (January-June); 6(2)

10. Henshaw RC, Templeton AA. Pre-operative cervical preparation before first trimester vacuum aspiration randomised controlled comparison between gemeprost and mifepristone. $\mathrm{Br} \mathrm{J}$ Obstet Gynaecol. 1998; 105: 413-7.

11. Tang OS, Schweer H, Seyberth HW, Lee SWH, Ho PC. Pharmacokinetics of different routes of administration of misoprostol. Hum Reprod. 2002;17(2): 332-6

12. Gangualy RP, Saha SP, Mukhopadhyay S, Bhattacharjee N, Bhattscharya SK, Patra KK. A comparative study on sublingual versus oral and vagina; administration of misoprostol for late first and early second trimester abortion. J Indian Med Assoc. 2010; 108(5):284-6.

13. Vimala N, Mittal S, Kumar S, Dadhwal V, Sharma Y. A randomized comparison of sublingual and vaginal misoprostol for cervical priming before suction termination of first-trimester pregnancy. Contraception. 2004; 70(2): 117-20.

14. Hammoda H, Ashok Premila W, Flett Gillian MM, Templeton A. A randomized controlled trial of mifepristone in combination with misoprostol administered sublingually or vaginally for medical abortion up to 13 weeks of gestation. Br J Obstet Gynaecol. 2005;112: 1102-8.

\section{Varsha Kotwal ${ }^{1}$}

${ }^{1}$ Senior Consultant, Obstetrics and Gynecology, (Jammu and Kashmir). 